\title{
Real-time landslides monitoring and warning using RFID technology for measuring ground water level
}

\author{
S. Hosseyni ${ }^{1,2}$, E. N. Bromhead ${ }^{2}$, J. Majrouhi Sardroud ${ }^{2,3}$ \\ M. Limbachiya ${ }^{2} \&$ M. Riazi ${ }^{4}$ \\ ${ }^{1}$ Islamic Azad University, Azadshahr Branch, Iran \\ ${ }^{2}$ School of Civil and Construction Engineering, Kingston University, UK \\ ${ }^{3}$ Islamic Azad University, Central Tehran Branch, Iran \\ ${ }^{4}$ Consultant Engineer, UK
}

\begin{abstract}
Across the world, economic and social landslide losses have increased as human development has expanded into unstable onto hill slopes. Every landslide catastrophe produces a significant loss to infrastructures, services and buildings as well as resulting in large numbers of casualties and fatalities. Although ground water level is often a primary controlling factor in landsliding, modeling of ground water is difficult due to the complex internal geology in most landslides. There are different approaches to locate the ground water table. Field observations are vital. This research has focussed on the utilization of integrated applications of Radio Frequency (RF) technologies such as Radio Frequency Identification (RFID), with ultrasonic sensors for accurate and timely identification and monitoring of ground water level in slopes and landslide susceptible areas. RFID integrated with ultrasonic and temperature sensors provide an opportunity to monitor groundwater in landslide susceptible areas on a real-time basis. The transmission of data to the central database can be carried out with the help of Global System for Mobile Communications (GSM), and the collected data can be used for slope stability analysis.
\end{abstract}

Keywords: ground water level, landslide monitoring, ultrasonic, RFID. 


\section{Introduction}

Landsliding is a complex geological and geomorphological process that occurs when the resistance of the soil or rock deteriorates. Over the past few years, the incidence of landslide disasters increased as a result of human development onto hill slopes. In comparison to earthquake their effects are more easily mitigated. Monitoring and early warning systems are important. Although stabilization projects are an alternative treatment for unstable slopes, they are sometimes impracticable and not cost-effective. It can be argued that establishing an adequate monitoring and early warning system is a better an alternative option. Appropriate monitoring not only throws light on the issue of early warning, but also can help in understanding landslide processes.

There are different approaches to detect surface or subsurface movement such as: the use of survey markers; extensometers; inclinometers; analogue and digital photogrammetry, both terrestrial and aerial; and Interferometric Synthetic Aperture Radar (InSAR) and Ground-Based Synthetic Aperture Radar (GBSAR) and recently Web Geographical Information System platform (WebGIS) [1-3].

Among the main causal factors of landslides, the temporal variation of the groundwater level plays an important role on slope instability, so that it can be said that the ground water level is often the primary controlling factor in landslide occurrence. Recently, investigations have been carried out for modelling and estimating groundwater level in various conditions. The distributed three-dimensional groundwater model MODFLOW has been applied to evaluate the groundwater processes of the hydrogeological system within GIS [4]. Soil moisture was assessed by an airborne scatterometer by Blumberg et al. in 2000 [5]. They developed a multi-channel system as a remote sensor for mapping soil water content. In 2002 dynamic groundwater movement was monitored using Ground Penetration Radar (GPR) by Sato and Lu [6]. Water behavior inside the soil was simulated by a two-dimensional simulation model for prediction of rainfall triggered landslides [7]. Groundwater numerical modeling has been used to understand the patterns of groundwater flow in slopes and their impact on slope stability by several researchers [8]. An investigation of slopes endangered by rainfall induced landslides using high-resolution 2D and 3D electrical resistivity tomography (ERT) was carried out to derive detailed subsurface images by Friedel et al in 2006 [9, 10]. Multi-temporal images for groundwater level monitoring in arid areas was used in 2008 by Pan et al. [10]. A time domain reflectometry-based probe was used for monitoring water content in a high-clay landslide by Stangl et al. in 2009 [11]. The results from soil moisture probes and water levels revealed the surface infiltration process in an unsaturated soil so that the mechanism of failure of rainfall-induced landslides could be understood by Tu et al. [12] in the same year. Environmental sensors and sensor networks to develop water and salinity budgets for seasonal wetland real-time water quality management were investigated in 2010 by Quinn et al. [13]. 
In this research RFID and sensor technologies have been combined with other traditional groundwater monitoring techniques and rainfall gauges to provide real-time groundwater level information correlated rainfall. This cost effective and low power consumption system provides a fit-for-purpose approach to get the basic data for monitoring groundwater level change from distance. Data can be captured and saved continuously, far from the site in any weather condition even during a landslide. For best effect, automated record data systems should be coupled with dynamic software to acquire and save real-time continuous data and to visualise groundwater table areas. It gives a regional seasonal picture of groundwater level in the endangered areas. In addition, when the system is combined with rainfall gauges, it has the capability of providing reliable data for understanding the mechanisms and processes in which shallow and rainfall triggered landslides occurred, and subsequently the real relationships between rainfall infiltration and groundwater table can be obtained.

\section{Problem statements}

Landslide monitoring systems usually concentrate on ground movement, as this gives direct indication of developing instability. Groundwater monitoring on the other hand, needs to be interpreted through an appropriate stability model to be useful. It is important, therefore that if ground water monitoring is undertaken, that the measurement of water level is made in real time and is transmitted to a safe remote location for processing. The problems therefore lie within the areas of both data collection and transmission.

The following section describes the three basic technologies used in a data collection and transmission system. They are an ultrasonic sensor to measure the depth to the water table, driven by an RFID tag that can be activated remotely, and the GSM connection for data transmission.

\section{Wireless technologies}

Recent technological advancement in wireless sensor technologies and data acquisition systems provide potential for advanced consistent data collection and communication, and are both technically and economically feasible and viable [14].

Ultrasonic sensors are widely used in industrial applications to measure object distance recently. The operating principle is based on the measurement of the Time of Flight (T.o.F.), which is the time required for an ultrasonic wave to travel from a transmitter to a receiver. In T.o.F. technique, object distance (D) from the receiver is evaluated by $D=V \times$ T.o.F. where $\mathrm{V}$ is the sound velocity [15].

RFID is a method of remotely storing and retrieving data by utilizing radio frequency in identifying, tracking, and detecting various objects [16]. During the last few years, RFID technology has already taken its place as a prototype in civil engineering for identification and data acquisition [17] and has been successfully used in the areas of manufacturing, distribution, the supply chain, 
agriculture, transportation, and healthcare. An RIFD system consists of tags (transponders) with antenna, a reader (transceiver) is also antenna, and a host terminal. The RFID reader acts as a receiver and transmits an electromagnetic field that "wakes-up" the tag and provides the power required for the tag to operate [18]. An RFID tag is a portable memory device located on a chip that is encapsulated in a protective shell and can be attached to any object which stores information about the object. Tags consist of a small integrated circuit chip coupled with an antenna to enable them to receive and respond to radio frequency queries from a reader. RFID tags can be classified into active tags (battery powered) and passive tags, which powered solely by the magnetic field emanated from the reader and hence have an unlimited lifetime. Reading and writing ranges are depend on the operation frequency (low, high, ultra high, and microwave). Low frequency systems generally operate at $124 \mathrm{KHz}, 125 \mathrm{KHz}$ or $135 \mathrm{KHz}$. High frequency systems operates at $13.56 \mathrm{MHz}$ and ultra high frequency (UHF) and use a band anywhere from $400 \mathrm{MHz}$ to $960 \mathrm{MHz}$ [19]. Tags operating at ultra high frequency (UHF) typically have longer reading ranges than tags operating at other frequencies. Similarly, active tags have typically longer reading ranges than passive tags. Active tags have an internal battery source and therefore have a shorter lifetime of approximately three to ten years [18]. The reader, combined with an external antenna, reads/writes data from/to a tag via radio frequency and transfers data to a host computer [20]. RFID tags are not damaged easily and do not require line-of sight for reading and writing, they can also be read in direct sunlight and survive harsh conditions, reusable, and permit remote access [21].

GSM is a worldwide standard for cellular communications. One of the current available technologies for mobile data transfer is General Packet Radio Systems (GPRS). GPRS is a packet switched "always on" technology which allows data to be sent and received across a mobile telephone network almost instantly [22].

\section{Architecture of the proposed system}

The RFID-based pervasive system developed in this research is divided into three major parts, firstly the field or on-site monitoring system and secondly the office data processing system. The on-site system mainly consists of two types of hardware components; namely, (i) Groundwater Level Box (GWL-box) consisting of the transmitter/receiver, GSM module; (ii) digital rainfall gauge; (iii) Leveling Package (LP) which consists of an active RFID tag coupled with ultrasonic sensor, this also equipped with a temperature sensor. GSM communication technology is the second part of the mobile pervasive system where the information is retrieved from transmitter/receiver device and is transferred to the server using GPRS. Finally, the Data Processing System consists of two servers, the application server (e.g. GIS system) and the database server with warning system. The architecture of the system and the schematic model of collection, transmission and managing of data are shown in figure 1 . 


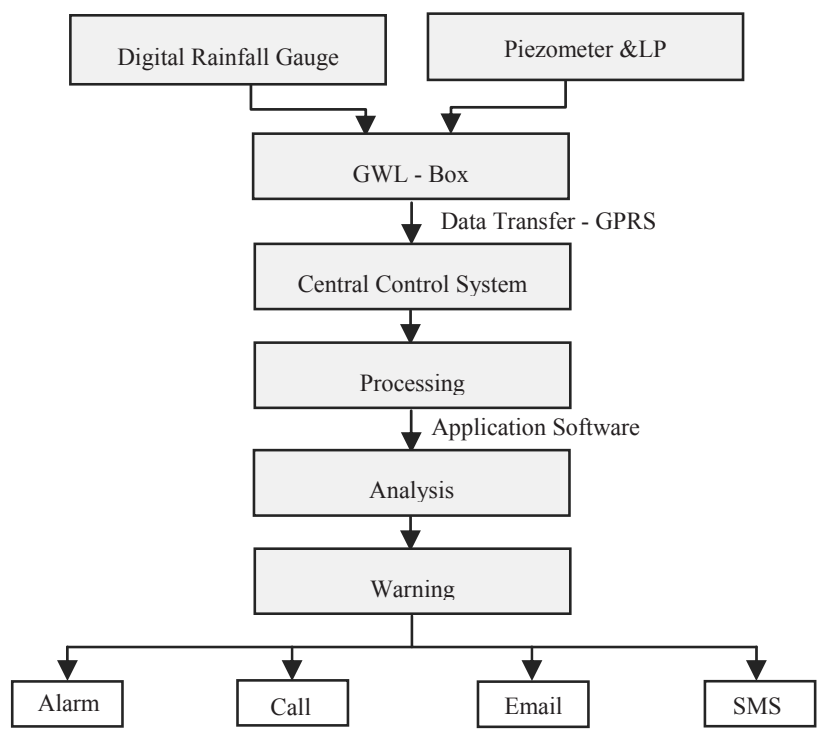

Figure 1: The system implementation flow diagram.

\section{Implementation}

To meet the requirements of real-time monitoring of the changes in pore water pressure in a given area, an intelligent network system gathers the required information continuously. The monitoring system, which combines sensor technologies with traditional method of groundwater level monitoring, piezometers, consists of the following subsystems:

\subsection{System installation and setup}

First of all, piezometers are located based on the geological and topographical maps of the area, using expert judgment. The numbers and location of piezometers can also be optimized using a neural network algorithm if necessary. For levelling up the water inside the piezometers, they have been left to stabilise. The main part of the proposed system is placed in the piezometer. The main function of this part is measuring the water level. This part of the system which is named LP consists of an active RFID tag coupled with an ultrasonic sensor equipped with a temperature sensor. This subsystem floats on the existing water in the piezometer using a small balloon. It has capability to receive RF waves and sends RF-ultrasound waves to and from the transmitter and receiver. Figure 2 illustrates a schematic scheme of the automated groundwater level monitoring system.

The heart of the system is the Groundwater Level Box (GWL-box). This includes a transmitter/receiver and GSM module. The GWL-box sends the collected data continuously, however, in order to detect the box from landsliding 
it is highly recommended to install the box on a concrete platform and in the more stable zone of the area. The transmitter/receiver can collect the data regarding the water level from the piezometer and also get rainfall data from the recorder by wire.

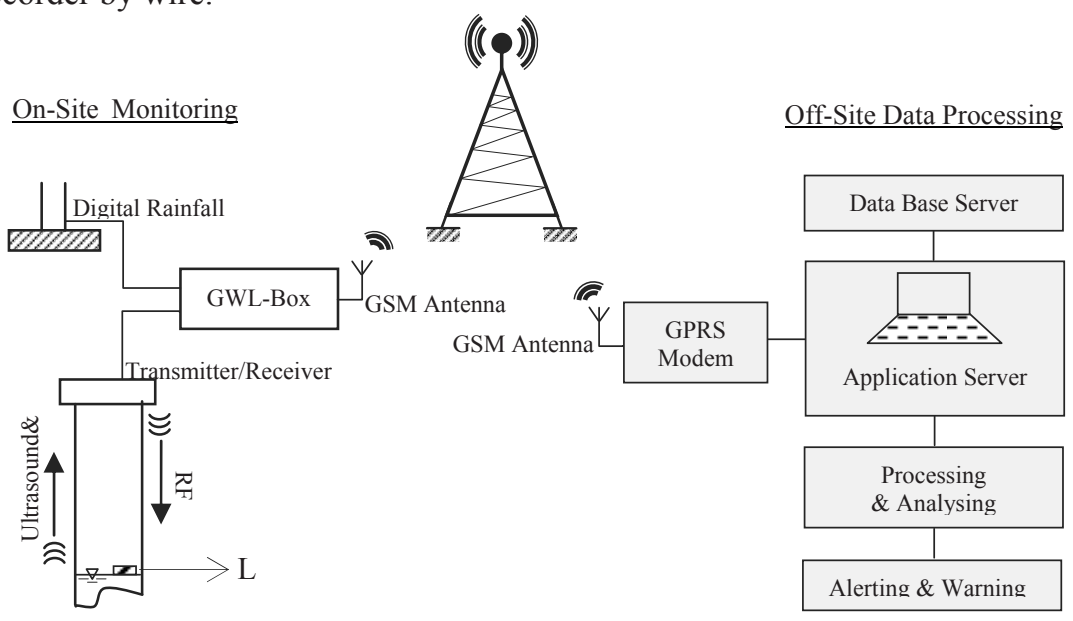

Figure 2: Schematic scheme of the automated groundwater monitoring system.

As illustrated in figure 3, the transmitter and receiver can be packed and secured as the cap of the piezometer. The main performance of this part of the system is sending RF waves towards the active RFID-Sensors (LP) and receiving $\mathrm{RF}$ and ultrasound waves from the LP as well as transfer of the collected data to GWL-box.

The last on-site subsystem which is installed and connected directly to GWLbox is a digital rainfall recorder. This peripheral device has the capability of data retrieval by data shuttle directly to GWL-box and is equipped with a solar power supply.

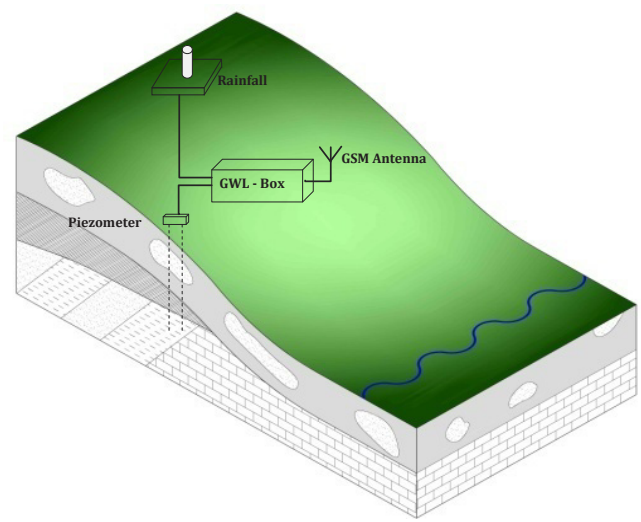

Figure 3: Schematic model of system installation. 
This linkage between the two subsystems, LP and digital rainfall gauge, provides the advantage of continuous data collection even in adverse climatic conditions, so that sophisticated data collection is possible for slope instability prediction in the future.

\subsection{Triggering and depth calculation}

As it was mentioned, the Leveling Package (LP) floats on the water inside the piezometer measuring its water level. On the measurements of T.o.F. for RF to estimate the distance of tag from the receiver, the delay is attributed to the speed of RF (very fast travelling) signals in the space. In order to find a solution for this issue and to have a more accurate measurement for distance, an ultrasound signal is used to measure the distance of sensor from the receiver. Therefore, an estimation of distance starts with a query from transmitter and at the same time a timer starts and the tag responds to the ultrasound signal within a short time after a querying of the receiver. Thus, the signal travels with the speed of light in the forward direction and with the speed of ultrasound in the backward direction where the speed of ultrasound signals is about $340 \mathrm{~m} / \mathrm{s}$ which is significantly slower than the speed of light (one million times slower than the speed of light). Therefore small delays identified by scheduling the sensor do not cause an error in estimation of distance and we can ignore the component of the delay recognized by the small processing or scheduling delay at the sensor, or the propagation delay of RF signal in the forward direction. The ultrasound signal does not carry in digital information, thus RFID active tag has been selected for transferring data such as temperature which is connected to the tag.

The intensity of the ultrasonic wave generated by the transmitter and the sensitivity of the receiver depends on the temperature of the environment which leads to a strong temperature dependence of the reflected intensity. The propagation time also depends on the temperature of the propagation environment (i.e. air).

The speed of sound in air actually depends on the temperature of the air. As a standard, it is accepted that the speed of sound is $340 \mathrm{~m} / \mathrm{s}$ at $15^{\circ} \mathrm{C}$. In order to calculate the speed of sound at a different temperature, this formula is used:

$$
\mathrm{v}=331.5 \mathrm{~m} / \mathrm{s}+0.6 \mathrm{~T}
$$

which " $\mathrm{v}$ " is the velocity of sound $(\mathrm{m} / \mathrm{s})$ and $T$ is the temperature $\left({ }^{\circ} \mathrm{C}\right)$.

For example the properties of sound in air with temperature $T=20.0{ }^{\circ} \mathrm{C}$ are: Velocity V=343.7 m/s, Frequency $=500 \mathrm{~Hz}$, and Wavelength $=0.6874 \mathrm{~m}$.

Therefore, distance of tag (ground water level) is expressed by:

$$
\mathrm{D}=\mathrm{V} \times \mathrm{t}
$$

which " $\mathrm{t}$ " is the propagation time.

To calibrate dependencies on temperature which is mentioned above, a RFID tag connected to a temperature sensor has been selected to monitor temperature of the environment.

The system is based on the definite interval time to capture and transfer the data remotely. The system can be programmed and interval time can be changed according to the seasonal demands. 


\subsection{Data collection and transmission}

At the allocated interval time the upper part of the piezometer triggers which sends RF waves to get radio frequency and ultrasound from LP. This data contains the proper information which is necessary to calculate water level according to the temperature. The GWL-box, figure 4, collects the information from transmitter. Then it firstly stores the collected data and transfers them to the main server using General Packet Radio Systems (GPRS) technology.

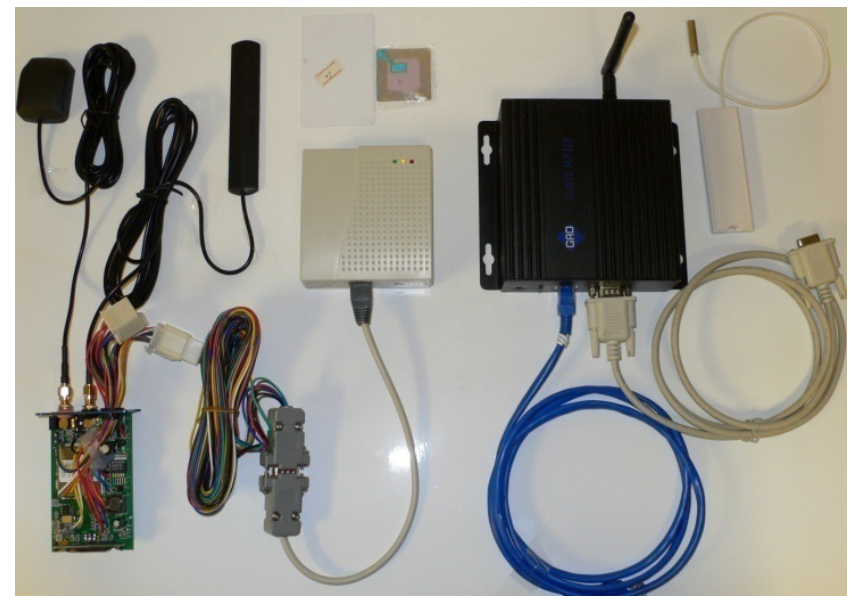

Figure 4: The GWL-box.

\subsection{Data processing and warning}

The prime location of devices, GWL-box, LP rainfall gauge, is identified with an unique ID. The GWL-box sends the collected data via GSM. When the data has been transferred to the main central computer, it can be recognised from the device data it was sent from. Special software has been written to calculate and correlate water levels and illustrate the water table and pore water pressures on real-time bases, graphically. The processed data is used for slope stability analysis and a factor of safety is calculated. Thereafter it is possible to predict what will happen in the next few hours and further potential dangers can be recognised in the pre-analyses of the slopes. While the factor of safety approaches one, a warning procedure is released. At this stage the results can be shown on a GIS map to recognize the slope failure location and the areas at risk. Then by means of the internet and GSM technology results are distributed, firstly to authorized people who are responsible for the area as well as the alert signals which are set up in the endangered area. The warning system has the ability to send text messages to provided mobile telephone numbers, and send email to local authorities in order to trigger the installed alarms. 


\section{Conclusions}

This paper investigates the applications of RFID-based system integrated with, GSM, and sensor technologies to automate the task of landslides monitoring and early warning by means of acquire groundwater table and pore water pressure on a real time bases. This system can provide low-cost, low energy consumption and timely active groundwater information on the slope areas with greater accuracy by using RFID technology. Such intelligent systems permit real-time control, enabling actions to be taken which will save valuable time. This research is conducted to identify opportunities for applying advanced tracking and data storage technologies in landslides monitoring and early warnings and to develop a model that explores how these technologies can be used in landslide monitoring.

\section{References}

[1] Petley D., Mantovani F., Bulmer M. and Zannoni A., "The use of surface monitoring data for the interpretation of landslide movement patterns," Geomorphology, vol. 66, pp. 133-147, 2005.

[2] Ayalew L., Yamagishi H., Marui H. and Kanno T., "Landslides in Sado Island of Japan: Part I. Case studies, monitoring techniques and environmental considerations," Engineering Geology, vol. 81, pp. 419-431, 2005.

[3] Xiao-gen L., An-ming W. and Zong-min W., "Stability analysis and monitoring study of Jijia River landslide based on WebGIS," Journal of Coal Science \& Engineering, vol. 16, pp. 41-46, 2010.

[4] Bonomi T. and Cavallin A., "Three-dimensional hydrogeological modelling application to the Alvera mudslide (\$Cortina d'Ampezzo, Italy)," Geomorphology, vol. 30, pp. 189-199, 1999.

[5] Blumberg D., Freilikher V., Lyalko I., Vulfson L., Kotlyar A., Shevchenko V. and Ryabokonenko A., "Soil Moisture (Water-Content) Assessment by an Airborne Scatterometer: The Chernobyl Disaster Area and the Negev Desert," Remote Sensing of Environment, vol. 71, pp. 309-319, 2000.

[6] Sato M. and Lu Q., "Ground water migration monitoring by GPR," in 2002, pp. 345.

[7] Basile A., Mele G. and Terribile F., "Soil hydraulic behaviour of a selected benchmark soil involved in the landslide of Sarno 1998," Geoderma, vol. 117, pp. 331-346, 3-4.

[8] Jiao J., Wang X. and Nandy S., "Confined groundwater zone and slope instability in weathered igneous rocks in Hong Kong," Engineering Geology, vol. 80, pp. 71-92, 2005.

[9] Friedel S., Thielen A. and Springman S., "Investigation of a slope endangered by rainfall-induced landslides using 3D resistivity tomography and geotechnical testing," Journal of Applied Geophysics, vol. 60, pp. 100$114,2006$. 
[10] Pan S., Wang Z., Su Q., Sun T. and Zhang Y., "Groundwater Level Monitoring Model Using Multi-Temporal Image in Arid Region of Northwest China," The International Archives of the Photogrammetry, Remote Sensing and Spatial Information Sciences, vol. XXXVII, pp. 745750, 2008.

[11] Stangl R., Buchan G. and Loiskandl W., "Field use and calibration of a TDR-based probe for monitoring water content in a high-clay landslide soil in Austria," Geoderma, vol. 150, pp. 23-31, 2009.

[12] Tu X., Kwong A., Dai F., Tham L. and Min H., "Field monitoring of rainfall infiltration in a loess slope and analysis of failure mechanism of rainfall-induced landslides," Engineering Geology, vol. 105, pp. 134-150, 2009.

[13] Quinn N., Ortega R., Rahilly P. and Royer C., "Use of environmental sensors and sensor networks to develop water and salinity budgets for seasonal wetland real-time water quality management," Environmental Modelling \& Software, vol. 25, pp. 1045-1058, 2010.

[14] Majrouhi Sardroud J. and Limbachiya M., "Improving construction supply chain management with integrated application of RFID technology and portal system," in The 8th International Conference on Logistics Research (RIRL 2010), 2010.

[15] Majrouhi Sardroud J. and Limbachiya M., "Effective Information Delivery at Construction Phase with Integrated Application of RFID, GPS and GSM Technology," Lecture Notes in Engineering and Computer Science, vol. 2183, pp. 425, 2010.

[16] Jang W. and Skibniewski M., “A wireless network system for automated tracking of construction materials on project sites," Journal of Civil Engineering and Management, vol. 14, pp. 11-19, 2008.

[17] Jaselskis E., Anderson M., Jahren C., Rodriguez Y. and Njos S., "Radio Frequency Identification Applications in Construction Industry," Journal of Construction Engineering and Management ASCE, vol. 121, pp. 189-169, 1995.

[18] Erabuild, "Review of the current state of radio frequency identification (RFID) technology, its use and potential future use in construction," Tekes, Formas and DTI, 2006.

[19] Lahiri S., RFID Sourcebook. United States: IBM Press, 2005.

[20] Majrouhi Sardroud J., Limbachiya M. and Saremi A., "An overview of RFID application in construction industry," in Third International RFID Conference, 2009.

[21] Marioli D., Narduzzi C., Offelli C., Petri D., Sardini E. and Taroni A., "Digital Time-of-Flight Measurement for Ultrasonic Sensors," IEEE Transaction on Instrumentation and Measurement, vol. 41, pp. 93-97, 1992.

[22] Ward M., Thorpe T., Price A. and Wren C., "Implementation and Control of Wireless Data Collection on Construction Sites," ITcon, vol. 9, pp. $297-$ $311,2004$. 